Atıf için / For Citation: N. ŞAHİN, "Düşük basınçta indüktif bağlı radyo-frekans neon akan deşarjın özellikleri", Süleyman Demirel Üniversitesi Fen Edebiyat Fakültesi Fen Dergisi, 14(2), 213-226, 2019.

\title{
Düşük Basınçta İndüktif Bağlı Radyo-Frekans Neon Akan Deşarjın Özellikleri
}

\author{
Neslihan ŞAHIN ${ }^{* 1}$ \\ ${ }^{1}$ Eskişehir Teknik Üniversitesi, Fen Fakültesi, Fizik Bölümü, 26470, Eskişehir, Türkiye \\ *yazlşllan yazar e-posta: neslihansahin@eskisehir.edu.tr
}

(Alınış / Received: 01.06.2019, Kabul / Accepted: 31.07.2019, Yaylmlanma / Published: 30.11.2019)

Özet: İndüktif olarak bağlı radyo-frekans (RF) deşarj odasında 0,17 mbar ile 1,4 mbar arasındaki basınçlarda bulunan neon $(\mathrm{Ne})$ deşarjını karakterize etmek için optik emisyon spektrumları kullanılmıştır. 13,56 MHz frekansında 100, 160 ve $200 \mathrm{~W}$ çıkış güçlerinde çalışan RF güç kaynağı ile kuvars deşarj odasının iki farklı bölgesinde saf neon gazının akan deşarjı elde edilmiştir. Bu farklı iki bölgenin optik emisyon spektrumları 200-1200 nm dalga boyları aralığında elde edilmiştir. Amaç seçilen iki farklı bölge için ayrı ayrı plazma optik özellikleri belirlemektir. Neon akan deşarjı için elde edilen spektral çizgiler 585,248 ve 724,516 nm dalga boyları arasındadır. İndüktif bağlı deşarj sisteminde yaklaşık 0,77 mbar basınçta elde edilen deşarjın spektral çizgilerinin şiddetleri maksimum olarak ortaya çıkmıştır. Her iki deşarj bölgesi için uyarılma ve elektron sıcaklıkları matematiksel modeller ile tahmin edilmiştir.

Anahtar kelimeler: İndüktif bağlı deşarjlar, Düşük basınç deşarj, Deşarjın optik özelikleri, Yüksek frekans ve RF deşarjlar

\section{The Properties of Inductive Coupled Radio-Frequency Neon Flowing Discharge at Low-Pressure}

\begin{abstract}
The optical emission spectra were used to characterize the neon (Ne) discharge in the inductive coupled radio-frequency (RF) discharge chamber at pressures between 0.17 mbar and 1.4 mbar. With the RF power source operating at 100, 160 and $200 \mathrm{~W}$ output power at 13.56 $\mathrm{MHz}$ frequency, flowing discharge of pure neon gas is obtained in two different regions of the quartz discharge chamber. The optical emission spectra of these two different regions were obtained in the wavelength range of 200-1200 $\mathrm{nm}$. The aim is to determine the optical properties of plasma for two different regions selected separately. The spectral lines obtained for the neon flowing discharge are between the wavelengths of 585.248 and $724.516 \mathrm{~nm}$. In the inductive coupled discharge system, the intensities of the spectral lines of discharge obtained at a pressure of approximately 0.77 mbar were maximum. It was attempted to estimate the excitation and electron temperatures for both discharge regions by mathematical models.
\end{abstract}

Key words: Inductive coupled discharge, Low pressure discharge, Optical properties of discharge, High frequency and RF discharge

\section{Giriş}

Maddenin dördüncü hali olan plazma, eşit miktarda serbest olarak pozitif ve negatif yük taşıyıcı parçacıklar içerir. Yaklaşık olarak aynı miktarda zıt işaretlere sahip plazma ortamı kararlı bir durumda yarı-nötr davranışta bulunur [1]. Plazma terimi ilk defa 1929'da Irving Langmuir tarafından kullanılmıştır [2]. Plazma oluşumu sırasında, plazma ortamında oluşan elektron ve parçacık etkileşimleri gibi çeşitli temel 
mekanizmalar günümüzde hala çok iyi bilinmemektedir [3]. Plazmanın özelliklerini belirlemek, güncel bir araştırma alanıdır. Bazı çalışmalarda yarı iletken üretiminde de kullanılabilen plazmanın düşük güçlerde elektron yoğunluğunu artırmak için öneriler verilmiştir [4].

Düşük basınçta megahertz $(\mathrm{MHz})$ ölçeğinde yüksek frekanslı güç kaynakları kullanılarak plazma oluşturulabilmektedir. Güç kaynakları göz önüne alınırsa; RF plazmalar ile alternatif akım, doğru akım ya da mikrodalga güç kaynakları ile elde edilen plazmalar arasında birtakım benzerlikler ve farklılıklar bulunmaktadır [5].

Laboratuvar koşullarında, düşük basınçta RF güç kaynakları ile soğuk plazmalar elde edilebilir. Soğuk plazmaların iyonlaşma dereceleri oldukça düşüktür. Gaz sıcaklığı ise elektron sıcaklığından çok daha düşüktür ve kararlılığı son derece yüksektir. Elektron sıcaklığı, termodinamik olarak dengede olmayan plazmanın iyonlaşmasını ve kimyasal süreçleri belirlemede kullanılabilir. Gaz sıcaklığı ve ısıl süreçler ise iyonizasyon ve kimyasal reaksiyonları etkilemez [6-9]. Etkileşim mekanizmaları düşük basınç plazmada elektronik çarpışmalar kullanılarak kontrol edilemeyebilir. Uyarılma ve temel duruma geçiş için mekanizmalar yalnızca elektron etkisi ile kontrol edilemediği için uyarılma sıcaklığı elektron sıcaklığından oldukça farklıdır. Plazma yaklaşık denge koşullarında bile olsa, uyarılma sıcaklığı elektron sıcaklığı olarak alınamaz. Sonuç olarak, plazmanın yerel olarak termodinamik dengede (LTE) olup olmadığı oldukça önemlidir [10].

İndüktif olarak bağlı plazma kaynakları çok uzun süredir kullanılmaktadır. Bu sistemler, üzerinden akım geçen bir bobinin plazma odasının etrafına sarılması ile elde edilir. Bobin üzerindeki akım plazma bölgesinde manyetik akı oluşturur. Faraday yasasına göre, zamanla değişen manyetik akı yoğunluğu selonoidal bir RF elektrik alanı oluşturur. Serbest elektronlar, bu selenoidal RF elektrik alanı ile hızlanır. Düşük basınçlarda indüktif bağlı plazmalar; LTE olmayan plazmalar olabilir [11]. Düşük basınçta indüktif olarak bağlı deşarjlar, parçacık hızlandırıcılardaki iyon kaynaklarıdır. Düşük gaz basıncında yüksek bir plazma yoğunluğu elde etmek ve elektrotların bulunmaması, bu deşarjları yeni bir teknolojinin geliştirilmesinde çekici kılmıştır. Bu nedenle indüktif deşarjlarda meydana gelen temel plazma olayları üzerinde çok fazla araştırma yapılmıştır [12]. İndüktif deşarjlar, fazladan bir dc manyetik alan gerektirmez ve RF güç kaynakları, $1 \mathrm{kHz}-10^{3} \mathrm{MHz}$ ile $500 \mathrm{MHz}$ arasındaki frekanslarda çalışmaktadır. Dolayısıyla, plazma sistemi merkezindeki plazma yoğunluğu difüzyon süreçleriyle de artar [13]. Bir elektromanyetik alan ve bu sistemdeki deşarj arasındaki temel etkileşimler, plazma sınırına yakın kılıflarda bulunur. $\mathrm{Bu}$ etkileşimler; gaz basıncına, uygulama frekansına ve plazma boyutuna bağlıdır [14].

Düşük basınçta plazma oluşturmak için vakum sistemine ihtiyaç duyulmaktadır ve elde edilen soğuk plazma bir vakum pompası ile elektrot arasından veya bobin içinden dışarı çekilebilir. $\mathrm{Bu}$ yöntem kullanılarak yapılan bazı çalışmalarda optik emisyon spektroskopi (OES) verilerine dayalı hesaplamalar için 2 farklı bölge belirlenmiştir. Elektrot arasından veya bobin içinden dişarı çekilerek elde edilen 2. bölge akan deşarjlar, elektrotlar arasında oluşan 1. bölge akan deşarjdan çok farklı özelliklere sahip olabilmektedir. 2. bölge akan deşarj, elektrotlar arasından uzaklaştırıldığı için deşarj yüksek elektrik alan etkisinden çıkarılır. Ayrıca, 2. bölge akan deşarjda yüksek enerjiye sahip iyonların olmadığg bilinmektedir [15-16]. 
RF plazmalar, endüstriyel uygulamalar için oldukça uygundur. Düşük basınçta RF plazmaları için en kullanışı deşarj sistemi 13,56 MHz frekansta çalışan paralel levhalı plazma sistemidir. Bu koşullarda, elektronlar uyarılmış durumdaki atomları birleştirmek ve molekülleri parçalamak için birkaç eV 1 sıl enerjiye sahiptir. Bu durum, kimyasal reaksiyonların oluşumunu sağlamaktadır. Diğer taraftan, elektron yoğunluğu düşüktür ve bu nedenle elektron gazının 1sı miktarı çok küçüktür ve bu durumda plazma, hassas yüzeylerde etkileşim için kullanılabilmektedir [17].

Argon ve helyum gibi soygazlar kullanılarak elde edilen deşarjlar hakkında yapılan çalışmalar literatürde oldukça fazla bulunmaktadır. Ancak, indüktif olarak bağlı RF Ne deşarjlar ile ilgili yeterince çalışma bulunmamaktadır. İndüktif olarak bağlı $\mathrm{RF} \mathrm{Ne}$ deşarjla ilgili bazı çalışmalarda çok farklı akım frekansı ile çalışan güç kaynağı kullanılmıştır. Bu çalışmalarda, elektron sıcaklığı ve elektron yoğunluğu gibi plazmanın bazı elektriksel ve optiksel özellikleri incelenmiştir. Yapılan bir diğer çalışmada Ne deşarjı Monte-Carlo yöntemiyle incelenmiş olup farklı basınçlarda oluşan yapıların dikey kesit görüntüleri elde edilmiştir. Diğer bir çalışmada ise soygazlar ile deşarj odasında plazma oluşturulduktan sonra vakum odasında geçiş yapan deşarjın elektron enerji dağılım fonksiyonları incelenmiştir. Ancak, yapılan çalışmalarda indüktif olarak bağlı RF Ne deşarjların 2. bölgedeki özellikleri OES tekniği ile incelenmemişstir [1821].

LTE olmayan plazmaların elektron sıcaklığını hesaplamak çok kolay değildir. LTE olmayan plazmalar Corona denge bölgesinde bulunmaktadır. Boltzmann dengesine göre, Corona dengesindeki ilgili enerji seviyeleri tam dolu değildir. Seviyelerin uyarılması ve uyarılmaması elektron çarpışmaları ile kontrol edilemez. Bu nedenle, LTE olmayan plazmanın elektron sıcaklığını belirlemek için modifiyeli Boltzmann yöntemi kullanılabilir [22-23].

Ele alınan bir sistemde deşarj oluşumunu; deşarj odasının geometrisi, deşarj odasının yapıldığı malzeme, kullanılan gazın kısmi basınc1, vakum odasında bulunan gazın basıncı, gaz akış hızı, elektrot malzemesi ve gaza uygulanan güç gibi birçok parametre etkiler [24]. Elektron sıcaklığı ve elektron yoğunluğu, düşük basınçlı deşarjların çalışma koşullarını belirlemek için en önemli plazma parametreleridir. Bu özelliklerin belirlenmesinde OES tekniği kullanılabilmektedir [25-28]. Bu yöntem elektromanyetik 1şıma ve madde arasındaki etkileşimden yararlanmaktadır [29]. OES analizi sadece atomları ayırmak için değil, aynı zamanda atomların çarpışmalı olarak uyarılmasını sağlamak için de kullanılan numuneye yeterli miktarda enerji verilmelidir. Atomlar ve iyonlar uyarılmış durumundan daha düşük enerji durumuna 1sıl ve ışıma enerjisi aracılığı ile geçiş yaparlar. OES aracılığı ile belirli dalga boyu aralığında kaydedilen 1şımanın şiddeti, parçacıkların yoğunluğunu belirlemede kullanılır. OES tekniğinin deşarj sistemine dışarıdan bir etkisi olmamaktadır. Bunun dışında bu teknik ucuz ve kullanışlıdır. Uyarılmış tüm atomlar ve iyonların karakteristik ışıması yaklaşık olarak aynı anda oluşabilir. Bundan dolayı oluşan spektral çizgi sayısı arttıkça, 1şıma aralıklarında yakın mesafeli spektral çizgilerin üst üste girişimi oluşabilir ve spektral çizgiler ayırt edilemeyebilir [30].

Elektron, iyon ve atomlar yerel olmayan termodinamik dengedeki plazmalarda dengeye ulaşamayabilirler. Sicaklığı belirlemede kullanılan farklı yöntemler vardır. Boltzmann yöntemi, bu yöntemlerden biridir ve elektron sicaklığı bulunurken aşağıdaki denklemden yararlanılır [10]: 


$$
\ln \left(\frac{I_{p q} \lambda_{p q}}{g_{p} A_{p q}}\right)=-\frac{E_{p}}{k_{B} T_{u}}+\text { sabit }
$$

Burada; spektral çizgilerin şiddeti,

$$
I_{p q}=\frac{h c A_{p q} g_{p} n}{\lambda_{p q} U(T)} e^{\left(-\frac{E_{p}}{k_{B} T_{u}}\right)}
$$

ile verilmektedir [31]. Denklem 2'deki ifadeler;

$I_{p q} \quad: p$ enerji seviyesinden $q$ enerji seviyesine geçişin şiddeti

$\lambda_{p q} \quad: p$ enerji seviyesinden $q$ enerji seviyesine geçişin dalga boyu

$h \quad$ : Planck sabiti

c : Işık hızı

$n \quad$ : Işıma yapan parçacıkların sayı yoğunluğu

$U(T)$ : Kismi fonksiyon

$A_{p q} \quad: p$ enerji seviyesinden $q$ enerji seviyesine geçiş olasılığ

$k_{B} \quad$ : Boltzmann sabiti

$T_{u} \quad$ : Uyarılma sicaklığ

$g_{p} \quad$ : Üst enerji seviyesinin istatistiksel ağırlı̆̆

$E_{p} \quad:$ eV biriminde $p$ üst enerji seviyesi

olarak verilmektedir. Geçiş olasılığı, enerji seviyeleri ve istatistiksel ağırlıklar sabittir ve bu ifadelerin değerleri her bir dalga boyları için NIST veri tabanından elde edilmektedir [32]. Bu yöntem, LTE olmayan plazmada uyarılma sıcaklığının bulunması için yardımcı olur. LTE olmayan plazmalarda elektron sicaklığı, serbest elektronların kinetik sicaklığ ile ilişkili olan uyarılma sıcaklığından farklı olduğu için modifiye edilmiş Boltzmann eğrisi yöntemiyle hesaplanmalıdır [33]. Elektron sıcaklığının yüksek ve elektron yoğunluğunun çok düşük olduğu durumda, sadece iki süreç çok önemlidir. Bu süreçlerden biri, elektron etkisiyle taban durumunda bulunan parçacıkların uyarılma süreçleridir ve bir diğeri ise uyarılmış parçacıkların anlık 1şımasıdır [31, 34-36].

Elektronların Maxwell dağılımına uyduğu düşünülürse şiddet Denklem 3 ile tanımlanır [31]:

$$
I_{p q}=\frac{n(p) A_{p q} h c}{\lambda_{p q} 4 \pi}
$$

O halde, Denklem 4

$$
\ln \left(\frac{I_{p q} \lambda_{p q}}{A_{p q} g_{p} b(p)}\right)=\ln \left(\frac{n_{t} h c}{4 \pi U\left(T_{e}\right)}\right)-\left(\frac{E_{p}}{k_{B} T_{e}}\right)
$$

yazılabilir. Burada $n_{t}, b(p)$ ve $A_{p q}$ sirasıyla toplam nüfus yoğunluğu, saha parametresi ve Einstein katsayısıdır. Burada; $\frac{h c}{\lambda_{p q}}$ terimi enerji olarak tanımlanmaktadır. 
Uyarılma sıcaklığı; uyarılma enerjisi ve $\ln \left(\frac{I_{p q} \lambda_{p q}}{A_{p q} g_{p} b(p)}\right)$ arasında çizilen Boltzmann eğrisinin eğiminden hesaplanabilir. $\ln \left(\frac{I_{p q} \lambda_{p q}}{A_{p q} g_{p}}\right)$ ve $\ln \left(\frac{I_{p q} \lambda_{p q}}{A_{p q} g_{p} b(p)}\right)$, nin uyarılma enerjisine göre grafikler çizilebilir. Elektron sıcaklığı ise $\ln p-\ln \left(\frac{I_{p q} \lambda_{p q}}{A_{p q} g_{p}}\right)$ denklemleri arasındaki ilişki kullanılarak, Denklem 5 ifadesi için çizilen grafikten elde edilir.

$$
\ln \left(\frac{I_{p q} \lambda_{p q}}{A_{p q} g_{p}}\right)=\ln \left(\frac{n_{t} h c b_{0}}{4 \pi U\left(T_{e}\right)}\right)-m \ln p-\left(\frac{E_{p}}{k_{B} T_{e}}\right)
$$

$\mathrm{Bu}$ grafikteki veriler için lineer bir eğri elde edilirse grafiğin eğiminden elde edilen $m$ değeri $\ln \left(\frac{I_{p q} \lambda_{p q}}{A_{p q} g_{p}}\right)+m \ln p$ de yerine yazılabilir. $\ln \left(\frac{I_{p q} \lambda_{p q}}{A_{p q} g_{p}}\right)+m \ln p$ ve $E_{p}$ arasında tekrar bir grafik çizilir ve tekrar burada elde edilen lineer eğrinin eğiminden $T_{e}$ elektron sıcaklığı hesaplanır. Elektron sicaklığı hesaplandıktan sonra $\ln \left(\frac{I_{p q} \lambda_{p q}}{A_{p q} g_{p}}\right)+E_{p} / k_{B} T_{e}$ ifadesinde yerine yazılır. Elde edilen sonuç ile $\ln p$ arasında çizilen grafiğin lineer fitinden tekrar grafiğin eğimi elde edilir. $\mathrm{Bu}$ işlemler ile ardışık olarak elde edilen elektron sıcaklıklarının arasındaki fark \%10 dan az olursa elde edilen değer elektron sıcaklığını verir. Burada; Denklem 6'da görüldüğ̈̈ gibi $p_{p}$ ifadesi

$$
p_{p}=\sqrt{\frac{13,6}{E_{\infty}-E_{p}}}
$$

ile verilmektedir ve $E_{\infty}$, iyonlaşma enerjisidir [37].

Sonuç olarak, kısmi olarak yerel termodinamik dengede uyarma ve iyonlaşma olayları elektronlar aracılığı ile oluştuğu için seviyelerin uyarılması ve 1şıması, elektron çarpışmalarıyla kontrol edilemez. Bu nedenle, LTE olmayan plazmaların elektron sıcaklığını hesaplamak için modifiye edilmiş Boltzmann eğri yöntemi kullanılır [23].

Çalışmanın bundan sonraki bölümünde "materyal ve metot" tanımlanmıştır. Daha sonraki bölümde ise, OES analiz sonuçları verilerek, uyarılma sıcaklığı ve elektron sıcaklığı gibi plazma özellikleri elde edilmiştir. Tartışma ve sonuç kısmında çalışmanın yeniliği ve önemi vurgulanmıştır.

\section{Materyal ve Metot}

Çalışmada kullanılmış olan indüktif bağlı deşarj sisteminin şematik gösterimi Şekil 1'de verilmiştir. Silindirik bir şekle sahip olan kuvars (cam) deşarj odasının uzunluğu 35 cm'dir. Şekil 1' den görüldüğü gibi deşarj odasının altı adet kolu bulunmaktadır. Bu kolların her birinde ise çelik flanjlar bulunmaktadır. Çelik flanjların yarıçapları ise yaklaşık 1,5 cm'dir. Saf Ne gazı, deşarj odasının üst konumundaki flanj aracılığı ile deşarj odasına gönderilmiştir. RV8 Edwards vakum pompası dik konumdaki deşarj odasının altında bulunan flanj aracılığı ile sisteme bağlanmıştır. Sistemde bulunan hava vakum pompası aracılığı ile boşaltılmıştır. Gaz akışının olduğu durumda deşarj odasında ölçülen saf Ne gaz basıncı 0,17 mbar ile 1,4 mbar arasında değişmektedir. Ne gaz akış hızı, kütle akış ölçer ile kontrol edilerek 0,05-0,20 1/dk arasında alınmıştır. Deşarj odasının üstünde bulunan flanjın hemen altında bulunan cam borunun etrafına 8 
sarımlı bakır bobin sarılmıştır. Bu bobinin yüksekliği ve çapı, sırasıyla, $8 \mathrm{~cm}$ ve $6,5 \mathrm{~cm}$ ' dir.



Şekil 1. İndüktif bağlı radyo-frekans deşarj sistemi

Deşarj sistemi içerisinde deşarj oluşturmak için RF eşleştirme ünitesi ve Cesar 13,56 $\mathrm{MHz}$ RF jeneratörden oluşan güç kaynağı kullanılmıştır. Güç kaynağı indüktif deşarj oluşturmak için bakır bobine bağlanmıştır. Bu güç kaynağ 1 ve bobin aracılığ1 ile deşarj odasının hemen üst kısmında deşarjın elde edildiği yere 1. bölge denilmiştir ve böylece, manyetik alan tarafından indüktif bağlı deşarj oluşturulmuştur. Deneysel çalışmalar esnasında 100, 160 ve $200 \mathrm{~W}$ RF güçleri kullanılmıştır. Vakum pompası aracıllı̆̆ ile bobin içinde oluşan deşarj, deşarj odasının altına doğru çekilmiştir. Burada oluşmuş akan deşarj bölgesi de 2. bölge olarak belirlenmiştir. Akan deşarj bölgelerinde oluşan parçacıkların tanımlanması için emisyon çizgi spektrumları elde etmek için Ocean Optics HR2000 + spektrometre kullanılmıştır.

\section{Bulgular}

Bu çalışmada Şekil 2' de görüldüğü gibi deşarj odası etrafina sarılan bakır bobine RF güç kaynağının bağlanması ile deşarj elde edilir. Akımın neden olduğu elektrik alan bir manyetik alan indükler. Elektrik alan çizgileri birbirine yakın ve paraleldir. Bobin içerisindeki manyetik alan etkisi bobinden uzaklaştıkça azalır. Manyetik alanın parçacıklarla olan etkileşimi değişir. Bu durum plazmanın oluşumunu etkiler. Bundan dolayı, bobin içerisinde oluşan plazma bölgesi 1. bölge, bobin dışındaki plazma bölgesi ise 2. bölge olarak belirlenmiştir.

Optik emisyon spektrumu cihazı ile plazma tarafından soğurulan ve ortaya çıkan ışımanın elde edilmesi ve analiz edilmesi plazmanın belirli özellikleri hakkında bilgi verir. Aynı zamanda, spektral çizgiler ortamda bulunan farklı parçacıkların yoğunlukları hakkında da bilgi verir. OES cihazı deşarj ortamını ihmal edilebilir seviyede çok az tedirgin eder. $\mathrm{Bu}$ nedenle OES analiz tekniği, deşarjdaki elektron sıcaklığının hesaplanması ve farklı parçacıkların belirlenmesinde çok faydalı bir yöntemdir. Elektron sicaklığı ve elektron yoğunluğu, çarpışmalar sırasında oluşan aktif 
parçacıkların oluşumunu belirler. Dolayısıyla reaktif parçacıkların reaksiyonu, elektron sicaklığg ile dolaylı olarak kontrol edilebilir.

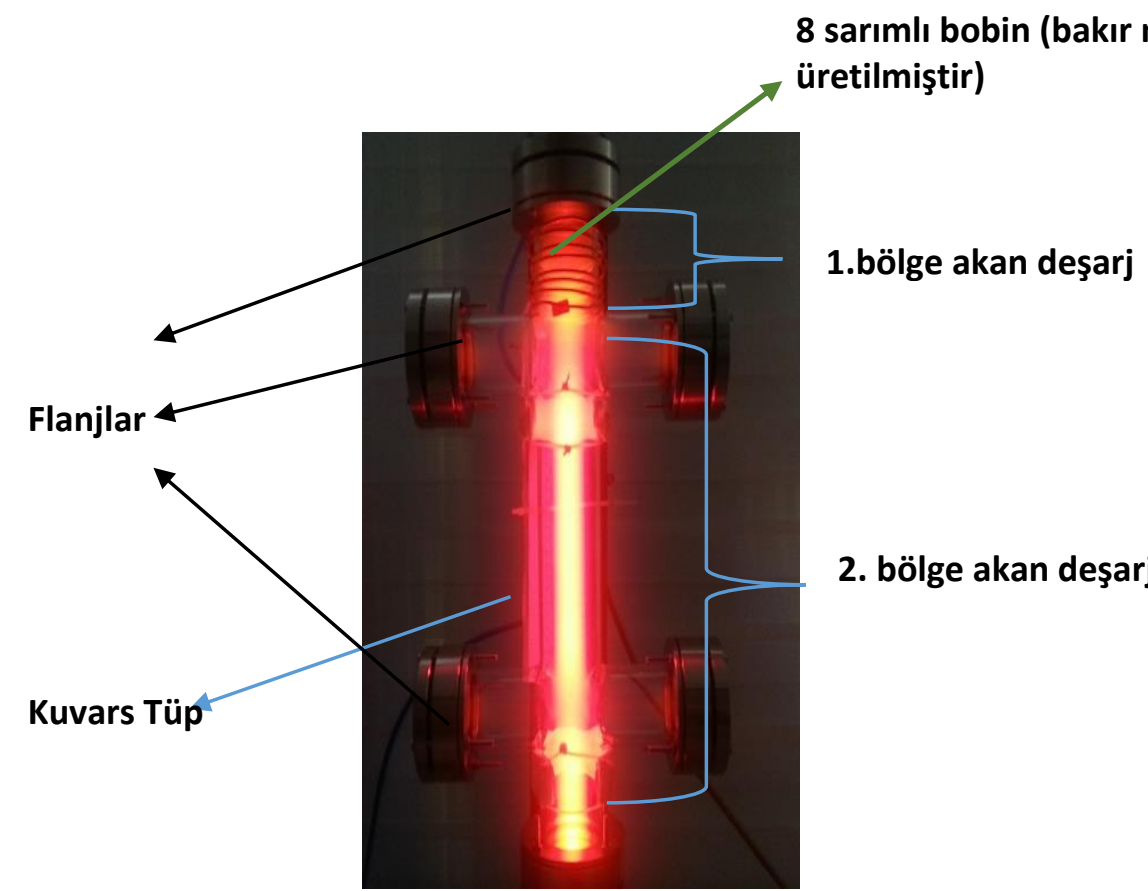

Şekil 2. Laboratuvar koşullarında düşük basınçta radyo-frekans Ne 1. ve 2. bölge akan deşarj

Şekil 2' de görülen Ne gaz akan deşarj için $g_{q} A_{p q}$ istatistiksel ağırlık ile Einstein katsayısının çarpımları, $E_{q}$ alt enerji seviye değerleri ve $E_{p}$ üst enerji seviye değerleri Tablo 1'den görülebilmektedir. Optik emisyon spektrumlarından da görüleceği gibi spektral çizgiler 585,248 ve 724,516 nm dalga boyu aralığında elde edilmiştir.

Tablo 1. Ne Deşarjından Elde Edilen Spektral Çizgiler (NIST) [32]

\begin{tabular}{ccccc}
\hline & Dalga Boyu & $\boldsymbol{g}_{\boldsymbol{q}} \boldsymbol{A}_{\boldsymbol{p q}}\left(\times \mathbf{1 0}^{\mathbf{7}} \boldsymbol{s}^{\mathbf{- 1}}\right)$ & $\boldsymbol{E}_{\boldsymbol{q}}(\mathbf{e V})$ & $\boldsymbol{E}_{\boldsymbol{p}}(\mathbf{e V})$ \\
\hline Ne I & 585,248 & 6,82 & 16,848 & 18,965 \\
Ne I & 594,483 & 5,65 & 16,619 & 18,704 \\
Ne I & 609,616 & 9,05 & 16,670 & 18,704 \\
Ne I & 614,306 & 14,1 & 16,619 & 18,636 \\
Ne I & 626,649 & 7,47 & 16,715 & 18,693 \\
Ne I & 633,442 & 8,05 & 16,619 & 18,575 \\
Ne I & 640,224 & 36,0 & 16,619 & 18,555 \\
Ne I & 650,652 & 15,0 & 16,670 & 18,575 \\
Ne I & 667,827 & 11,0 & 16,848 & 18,704 \\
Ne I & 671,704 & 6,51 & 16,848 & 18,693 \\
Ne I & 692,946 & 8,70 & 16,848 & 18,636 \\
Ne I & 703,241 & 7,59 & 16,619 & 18,381 \\
Ne I & 724,516 & 2,80 & 16,670 & 18,381 \\
\hline
\end{tabular}

Modifiye Boltzmann eğrisini elde etmek için Tablo 1' de görülen farklı uyarılma enerjilerine sahip spektral çizgiler seçilmektedir. 100, 160, $200 \mathrm{~W}$ RF güçlerinde 0,10 1/dk akış oranı için saf Ne gazının 1. ve 2. bölgedeki akan deşarjların dalga boyu-şiddet grafikleri Şekil 3 'te görülmektedir. Aynı zamanda farklı gaz akış oranlarında $200 \mathrm{~W}$ RF gücünde elde edilen saf Ne gazının 1. ve 2. bölgedeki akan deşarjların dalga boyu-şiddet grafikleri de Şekil 4'te görülmektedir. Şekil 3 ve 4'te görüldüğü gibi, çeşitli spektrum çizgileri deşarj odasında bulunan gazın cinsine, gaz akış hızına ve uygulanan RF gücüne bağlıdır. 

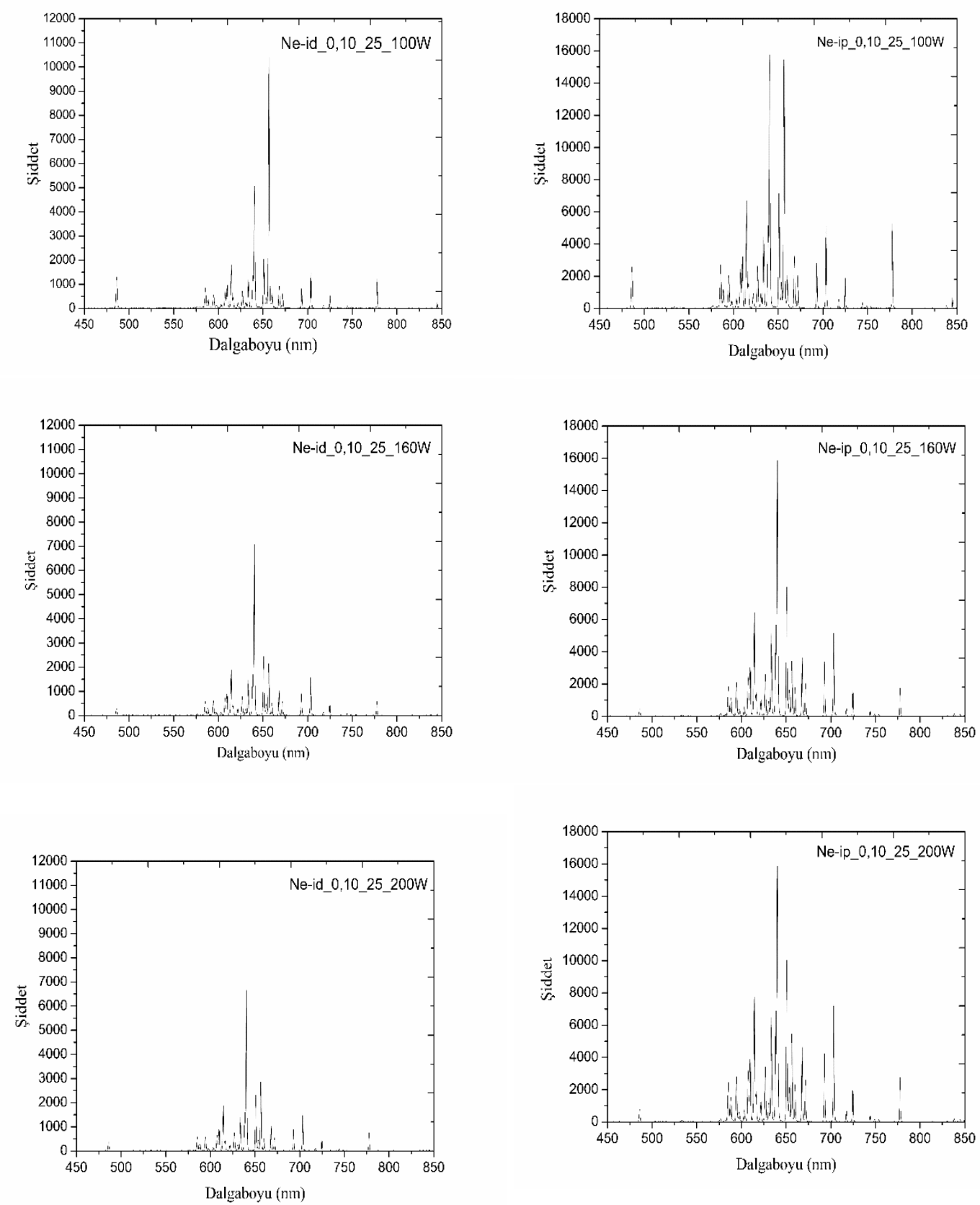

(a)

(b)

Şekil 3. 100, 160, $200 \mathrm{~W}$ RF güçlerinde 0,10 1/dk akış oranı için saf Ne gazının (a) 1. ve (b) 2. bölgedeki akan deşarjların dalga boyu -şiddet grafikleri 

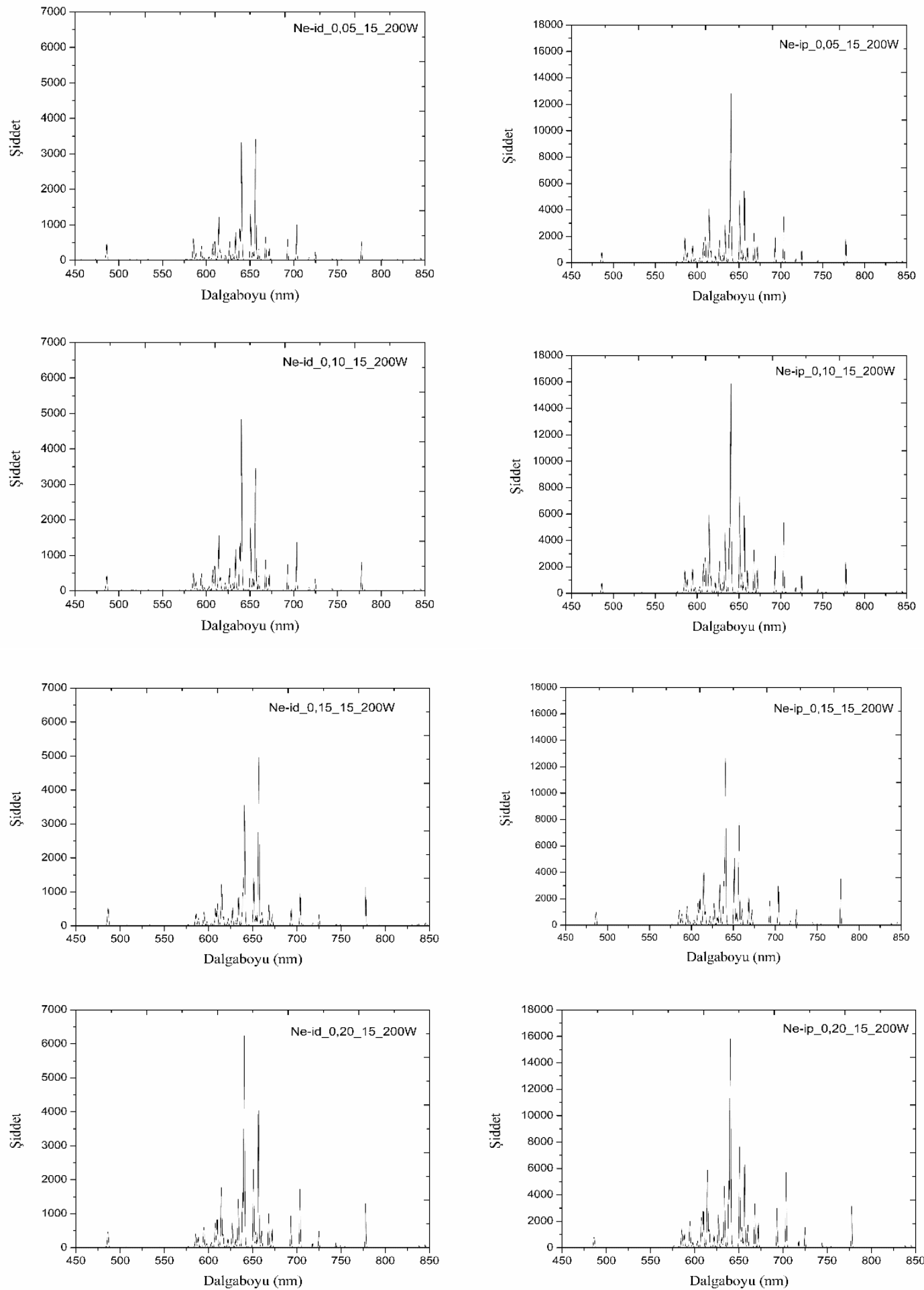

(a)

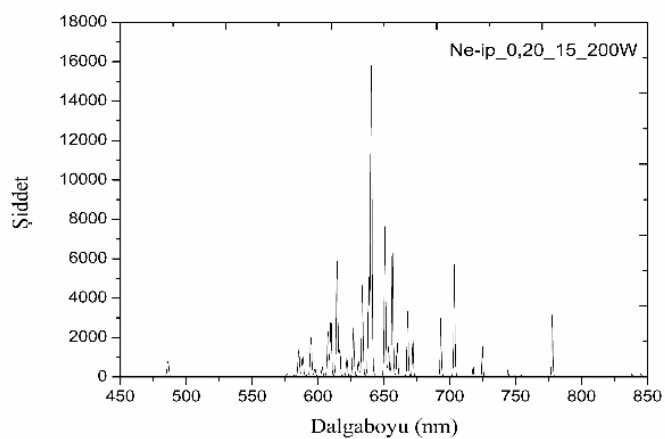

(b)

Şekil 4. Farklı gaz akış oranlarında $200 \mathrm{~W}$ RF gücünde elde edilen saf Ne gazının (a) 1. ve (b) 2 . bölgedeki akan deşarjların dalga boyu -şiddet grafikleri 
100,160 ve $200 \mathrm{~W}$ RF güçlerinde 0,05 ve 0,20 l/dk arasında değişen akış oranları için indüktif bağlı saf Ne gaz 1. ve 2. bölgedeki akan deşarjın uyarılma sıcaklıkları Şekil 5 'de görüldüğ ü gibi elde edilmiştir. Elektron sıcaklığı ise uyarılma sıcaklığını veren Boltzmann grafiği modifiye edilerek elde edilir.



(a)

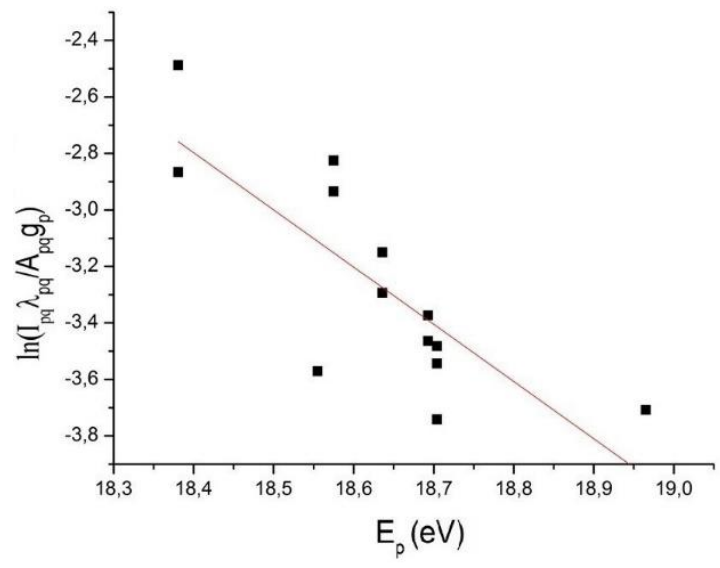

(b)

Şekil 5. (a) 1. bölgedeki ve (b) 2. bölgedeki akan deşarj için $\ln \frac{I_{p q} \lambda_{p q}}{A_{p q} g_{p}}-E_{p}$ grafiği

Bu çalışmada Şekil 5' den görüldüğü gibi belirlenen her iki bölgedeki akan deşarjların grafiklerinin eğiminden uyarılma sıcaklıkları için sırasıyla 0,39-1,25 eV ve 0,38-0,67 $\mathrm{eV}$ arasında elde edilmiştir. Bu sonuçlar literatürle de uyum içerisindedir. Eğer $m$ yani eğim değeri, Fujimotoya göre yaklaşık 6 ya eşit olursa plazma çarpışmalar içermektedir ve Boltzmann eğrisi modifiye edilmelidir [38-39].

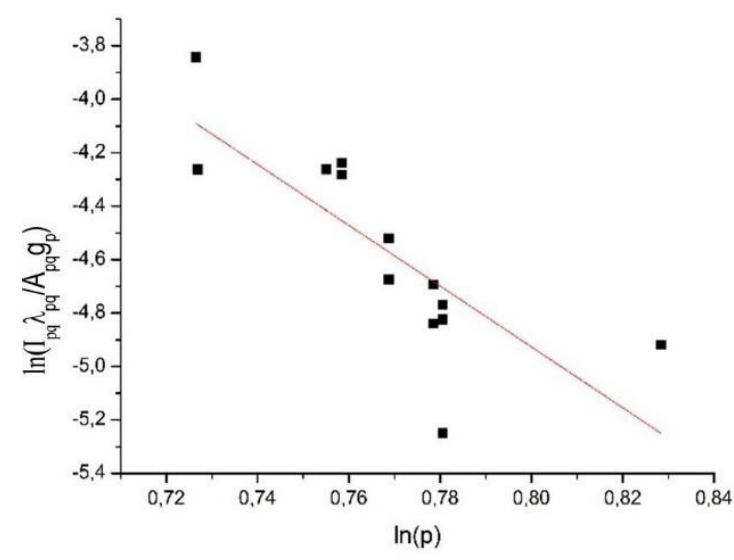

(a)

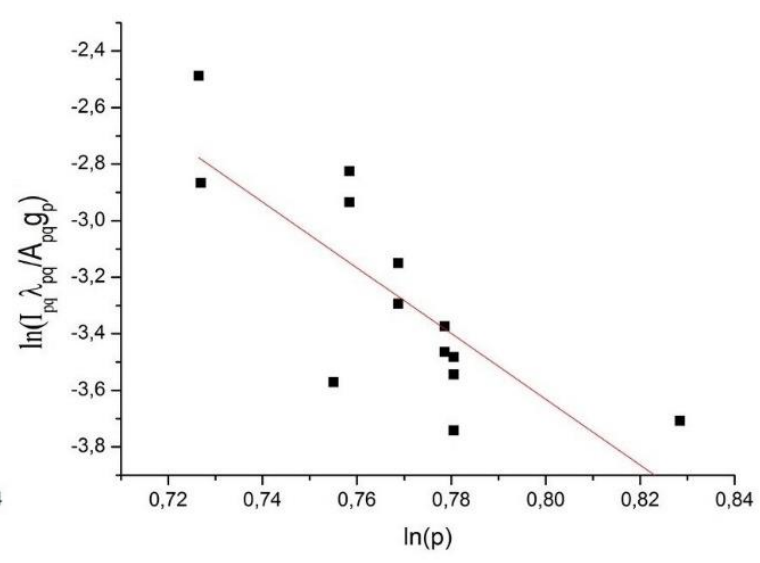

(b)

Şekil 6. (a) 1. bölgedeki ve (b) 2. bölgedeki akan deşarj için etkin kuantum sayısı- nüfus yoğunluğu

0,17-1,4 mbar basınç aralığında 100,160, $200 \mathrm{~W}$ RF gücü için 1. bölgedeki akan deşarjın elektron sıcaklığı 1,57 ve 5,65 eV olarak elde edilmiştir. 2. bölgedeki akan deşarj için elektron sicaklığı 1,99 ve 4,59 eV elde edilmiştir.

100, 160 and $200 \mathrm{~W}$ RF güçleri için her iki bölge için elde edilen elektron sıcaklıkları, ayrı ayrı Tablo 2' de görülmektedir. Farklı güçlerde sabit akış oranları için deşarj bölgesine birim zamanda giren parçacık sayısı sabittir. Özellikle 160 ve $200 \mathrm{~W}$ uygulanan güçte 1 . ve 2 . bölgedeki akan deşarj elektron sicaklığının arttığ gözlemlenmiştir. $\mathrm{Bu}$ artışın sebebi sürekli $\mathrm{RF}$ gücünün etkisiyle 1. bölge deşarjın 
parçacık sayısı sabitken elektronların sürekli olarak bu bölgesinde elektrik alan ile indüklenen enerji almasından kaynaklıdır ve bu yüzden deşarj odasının 2. bölgesindeki akan deşarj için elektron sıcaklıkları aynı şekilde artabilir.

Elektron nüfus yoğunluğu Denklem 7 ile hesaplanır [40]:

$$
n_{e}=10^{18} T_{e} Z^{\frac{7}{2}}\left(\frac{1}{n_{a}^{2}}\right)\left(\frac{2}{n_{b}}\right)^{5} \mathrm{~cm}^{-3}
$$

Burada $n_{a}$ ve $n_{b}$ sırasıyla alt ve üst seviyelerin baş kuantum sayılarıdır. Z; atom numarasını temsil etmektedir. Bu çalıșmada, 1. ve 2. bölgedeki akan deşarjlar için elektron nüfus yoğunlukları sirasiyla $1,41 \times 10^{13}-5,07 \times 10^{13} \mathrm{~cm}^{-3}$ ile $1,78 \times 10^{13}-4,12 \times 10^{13}$ $\mathrm{cm}^{-3}$ aralığında hesaplanmıştır. Elde edilen elektron yoğunluğu, elektron sicaklığı ve uyarılma sıcaklıkları Tablo 2' de verilmiştir. Elektron yoğunlukları ve sicaklıklarına göre plazma sınıflandırılması incelendiğinde bu değerler literatür ile uyum içerisindedir [20-41].

İndüktif olarak bağlanmış deşarjın çalışma modları, elektrostatik mod (E modu) ve elektromanyetik mod ( $\mathrm{H}$ modu) olarak bilinir. Sistemde kapasitif olarak iletilen güç, indüktif olarak iletilen güçten daha yüksek olduğunda, sistem E modunda çalışır [4]. Elektron sıcaklığı ve güç arasındaki ilişki incelendiğinde elde edilen deneysel sonuçlara göre 1 . ve 2 . bölgedeki akan deşarj için kullanılan güç ve $1 / T_{e}$ birbirleriyle ters orantılıdır. Tablo 2'de görülebileceği gibi 1. ve 2. bölgedeki akan deşarjın çalışma modunun E modundan $\mathrm{H}$ moduna geçtiği söylenebilir.

Tablo 2. Hesaplanan Bazı Uyarılma Sıcaklıkları, Elektron Sicaklığı ve Elektron Yoğunluğu

\begin{tabular}{cccc}
\hline Ne-Sistem Türü-Akış Oranı (l/dk)-Güç $(\mathbf{W})$ & $\begin{array}{c}\text { Uyarılma } \\
\text { Sıcaklığı } \\
(\mathbf{e V})\end{array}$ & $\begin{array}{c}\text { Elektron } \\
\text { Sıcaklı̆̆ı } \\
(\mathbf{e V})\end{array}$ & $\begin{array}{c}\text { Elektron Nüfus } \\
\text { Yoğunluğu } \\
\left(\mathbf{x 1 0} \mathbf{c m}^{-3}\right)\end{array}$ \\
\hline Ne-id-0.05-160 & 0.82 & 2.98 & 2.67 \\
Ne-id-0.05-200 & 1.25 & 1.57 & 1.41 \\
Ne-id-0.10-160 & 0.46 & 5.65 & 5.07 \\
Ne-id-0.10-200 & 0.51 & 4.08 & 3.66 \\
Ne-id-0.15-100 & 0.50 & 4.21 & 3.78 \\
Ne-id-0.15-160 & 0.42 & 3.86 & 3.46 \\
Ne-id-0.15-200 & 0.41 & 2.10 & 1.88 \\
Ne-id-0.20-100 & 0.39 & 4.11 & 3.69 \\
Ne-id-0.20-160 & 0.40 & 4.09 & 3.67 \\
Ne-ip-0.05-160 & 0.65 & 3.19 & 2.87 \\
Ne-ip-0.05-200 & 0.67 & 2.98 & 2.67 \\
Ne-ip-0.10-100 & 0.57 & 2.49 & 2.24 \\
Ne-ip-0.10-160 & 0.46 & 2.81 & 2.53 \\
Ne-ip-0.15-100 & 0.49 & 4.59 & 4.12 \\
Ne-ip-0.15-160 & 0.50 & 4.21 & 3.78 \\
Ne-ip-0.15-200 & 0.38 & 1.99 & 1.78 \\
Ne-ip-0.20-100 & 0.39 & 4.42 & 3.97 \\
Ne-ip-0.20-160 & 0.38 & 4.29 & 3.85 \\
\hline
\end{tabular}

(1.bölgedeki akan deşarj: id, 2.bölgedeki akan deşarj: ip)

\section{Sonuç ve Yorum}

Bu çalışmada RF güç kaynağı kullanılarak elde edilen indüktif bağlı Ne deşarj sistemin her iki bölgesindeki akan deşarjı ayrıntılı olarak incelenmiştir. Yüksek yoğunluklu 
indüktif RF deşarjlar, M.A. Lieberman ve A.J. Lichtenberg tarafından daha önce tanımlanmıştır [42]. Ancak, indüktif olarak bağlı RF Ne deşarjlar ile ilgili literatürde yeterli çalışma bulunmamaktadır. Yapılan çalışma ile 1. ve 2. bölgedeki akan deşarjların elektron sıcaklıkları ve OES sonuçları yeni bir bilgi olarak katkı sağlayacaktır [43-45]. Düşük basınçta 1. ve 2. bölge saf $\mathrm{Ne}$ akan deşarjın uyarılma sıcaklığı Boltzmann grafiği ile hesaplanmıştır. LTE olmayan plazmalar, Maxwell dağılım fonksiyonunu sağlamadığ için 1 . ve 2 . bölgedeki LTE olmayan akan deşarjın elektron sicaklığını hesaplamada OES sonuçlarından elde edilen spektral çizgilerinin kullanıldığ1 Boltzmann eğrisi modifiye edilmiştir.

Yapılan analizler sonucunda indüktif olarak bağlı kuvars (cam) deşarj odasının toplam basıncı, gazın akış hızı ve RF gücü, akan deşarjı etkilediği görülmüştür. Özellikle, elektron sıcaklığını ve yoğunluğunu etkilemektedir.

Plazmaya uygulanan güç arttığında, parçacıkların ortam içindeki iyonlaşması artar ve dolayısıyla plazmanın iletkenliğgi artar. Plazmanın iletkenliği arttığında, diğer parçacıklar elektrondan enerji kazanacaktır. Elektronlar enerjilerini ortamda oluşan çarpışma ile bu parçacıklara aktarır. Böylece, elektronların enerjileri düşer. Bu durum deşarj bölgesindeki elektronların sıcaklığının düşmesine neden olur. Elektron sıcaklığındaki düşüş, diğer uyarılmış hallerde parçacıkların uyarılmasını etkiler. Aynı basınç aralıkları için, kapasitif RF deşarj bölgelerindeki yoğunluk indüktif RF deşarjlardan yaklaşık 10 kat daha düşüktür. Akan deşarjların oluşum mekanizmasındaki farklılıklar, spektral çizgilerin şiddetinde farklılıklar vermektedir. Deşarj bölgesindeki parçacıkların elektrik alanından enerji kazanması 2. bölge akan deşarj odasında oluşan parçacıkların enerji kazanmasına neden olmaktadır. 2. bölge akan deşarj bölgesinde elektrik alan bulunmaz. Bu nedenle, bu bölgedeki parçacıkların enerji kaynağı, elektrik alandan kaynaklı değildir. Saf Ne gazın RF deşarj spektrumları 2. bölge akan deşarj spektrumlarından oldukça farklı olur.

Sistemde akan plazmalarda iki bölge belirlenmiştir. 1. ve 2. bölgedeki plazma parametre özelliklerinin ayrı ayrı incelenmesindeki amaç, bölgesel farklılıkların plazma parametrelerini farklı şekillerde nasıl etkiledikleri gözlemlemektir. Farklı iki bölgedeki akan deşarjın etkileri, uygulama yapılacak alanlar için farklı olacağı görülmektedir. Çünkü uygulama yapılacak alana göre malzeme, plazma deşarjının gerçekleştiği yere yerleştirilirse bu malzeme iyonlar, elektronlar, nötr radikaller, fotonlar ve diğer uyarılmış parçacıklarla her bir bölgede farklı bir etkileşime girer. Örneğin; malzeme 2. bölge deşarj bölgesine yerleştirilirse, numune sadece kararlı ve meta-stabil iyonik olmayan parçacıklarla etkileşime girer. $\mathrm{Bu}$ da uygulamada elde etmek istediğimiz sonuçları değiştirir. Daha sonraki çalışmalarda indüktif bağlı akan deşarjların çeşitli malzemelere uygulaması incelenebilir. 1. ve 2. bölgede göz önüne alınan akan deşarjın hangi modda (E-mod ve H-mod) çalıştığının daha ayrıntılı bir şekilde belirlenmesi de yararlı olacaktır.

\section{Teşekkür}

Bu çalışmanın ilerlemesine katkıda bulunan Prof. Dr. Murat TANIŞLI' ya değerli katkıları ve desteği için teşekkürlerimi sunarım.

\section{Kaynakça}

[1] W. Baumjohann, and R. A. Treumann, Basic Space Plasma Physics. London: Imperial College Press, 1997.

[2] L. Tonks, and I. Langmuir, “Oscillations in ionized gases,” Phys. Rev., 33 (2), 195, 1929. 
[3] J. Schulze, B. G. Heil, D. Luggenhölscher, and U. Czarnetzki, "Electron beams in capacitively coupled radio-frequency discharges," IEEE Trans. Plasma Sci., 36 (4), 1400-1401, 2008.

[4] X. Zhang, P. C. Yu, Y. Liu, Z. Zheng, L. Xu, P. Wang, and J. X. Cao, "The transition mechanisms of the $\mathrm{E}$ to $\mathrm{H}$ mode and the $\mathrm{H}$ to E mode in an inductively coupled argon-mercury mixture discharge," Phys. Plasmas, 22 (10), 103509, 2015.

[5] T. Kaneda, T. Kubota, M. Ohuchi, and J. S. Chang, "Time-averaged electric potential profiles in a capacitive-coupling parallel-plate electrode neon gas RF discharge plasma," J. Phys. D: Appl. Phys., 23 (12), 1642-1647, 1990.

[6] A. Friedman, Plasma Chemistry. Cambridge: Cambridge University Press, 2008.

[7] I. Tanarro, V.J. Herrero, E. Carrasco, and M. Jiménez-Redondo, "Cold plasma chemistry and diagnostics," Vacuum, 85 (12), 1120-1124, 2011.

[8] R. B. Heimann, Plasma- Spray Coating Principles and Applications. The Federal Republic of Germany: VCH, 1996.

[9] N. Zhang, F. Sun, L. Zhu, M. P. Planche, H. Liao, C. Dong, and C. Coddet, "Electron temperature and density of the plasma measured by optical emission spectroscopy in VLPPS conditions," $J$. Therm. Spray Tech., 20 (6), 1321-1327, 2011.

[10] F. J. Gordillo-Vazquez, M. Camero, and C. Go mez-Aleixandre, "Spectroscopic measurements of the electron temperature in low pressure radiofrequency $\mathrm{Ar} / \mathrm{H} 2 / \mathrm{C} 2 \mathrm{H} 2$ and $\mathrm{Ar} / \mathrm{H} 2 / \mathrm{CH} 4$ plasmas used for the synthesis of nanocarbon structures," Plasma Sources Sci. Technol., 15 (1), 42-51, 2006.

[11] A. Bogaerts, E. Neyts, R. Gijbels, and J. van der Mullen, "Gas discharge plasmas and their applications," Spectrochim. Acta Part B, 57, 609-658, 2002.

[12] V. A. Godyak, R. B. Piejak, and B. M. Alexandrovich, "Electron energy distribution function measurements and plasma parameters in inductively coupled argon plasma," Plasma Sources Sci. Technol., 11, 525-543, 2002.

[13] J. Hopwood, "Review of inductively coupled plasmas for plasma processing," Plasma Sources Sci. Technol., 1 (2), 109, 1992.

[14] A. Montaser, S. K. Chan, and D. W. Koppenaal, "Inductively coupled helium plasma as an ion source for mass spectrometry," Analytical Chemistry, 59 (8), 1240-1242, 1987.

[15] M. Tanışl, İ. Rafatov, N. Şahin, S. Mertadam, and S. Demir, "Spectroscopic study and numerical simulation of low-pressure radio-frequency capacitive discharge with argon downstream," Can. J. Phys., 95 (2), 190-200, 2017.

[16] M. Tanışli, and N. Şahin, "Optical characteristics for capacitively and inductively radio frequency discharge and post discharge of helium,” Phys. Plasmas, 23 (1), 13513, 2016.

[17] A. Piel, Plasma Physics: An Introduction to Laboratory, Space, and Fusion Plasma. New York: Springer, 2010.

[18] M. V. Isupov, and I. M. Ulanov, "Analysis of the parameters of plasma of an inductively coupled discharge in neon," High Temperature, 43 (2), 169-176, 2005.

[19] M. V. Isupov, I. M. Ulanov, and A. Yu. Litvintsev, "Experimental investigation of the electrical and optical characteristics of an inductively coupled discharge in neon," High Temperature, 42 (5), 682688, 2004.

[20] Z. I. Khattak, M. Shafiq, and A. W. Khan, "Investigation of plasma parameters during mode transition in magnetic-pole-enhanced-inductively coupled neon plasma," IEEE Trans. Plasma Sci. 47 (5), 2665-2674, 2019.

[21] C. A. DeJoseph Jr, V. I. Demidov, J. Blessington, and M. E. Koepke, "Investigation of a radiofrequency inductive-coupled-plasma discharge afterglow in noble gases," J. Phys. B: At. Mol. Opt. Phys., 40 (19), 3823-3833, 2007.

[22] H. R. Griem, Principles of Plasma Spectroscopy. Cambridge: Cambridge University Press, 1997.

[23] N. U. Rehman, M.A. Khan, M. Y. Naz, M. Shafiq, and M. Zakaullah, "Characterization of 13.56 $\mathrm{MHz}$ RF Ne- $\mathrm{N}_{2}$ mixture plasma using intrusive and non-intrusive diagnostic techniques," Phys. Scr., 88, 045503, 2013.

[24] A. Grill, Cold Plasma in Materials Fabrication from Fundamentals to Applications. New York: IEE Press, 1993.

[25] X. M. Zhu, and Y. K. Pu, "Using OES to determine electron temperature and density in low-pressure nitrogen and argon plasmas," Plasma Sources Sci. Technol., 17 (2), 024002, 2008.

[26] M. Tanışlı, N. Şahin, and S. Demir, "Comments on the Langmuir probe measurements of radiofrequency capacitive argon-hydrogen mixture discharge at low pressure," Can. J. Phys., 96 (5), 494500 (2018).

[27] M. Tanışlı, N. Şahin, M. Younus, N. U. Rehman, and S. Demir, "Optical and electrical properties of capacitive coupled radio frequency Ar- $\mathrm{H}_{2}$ mixture discharge at the low pressure," Phys. Plasmas, 24 (10), 102123 (2017). 
[28] M. Tanışl1, N. Şahin, and S. Demir, "An investigation on optical properties of capacitive coupled radio-frequency mixture plasma with Langmuir probe," Optik, 142, 153-162 (2017).

[29] V. N. Ochkin, Spectroscopy of Low Temperature Plasma. Weinheim, New York, Basel, Cambridge, Tokyo: VCH, 2009.

[30] C. B. Boss, and K. J. Fredeen, Concepts, Instrumentation and Techniques in Inductively Coupled Plasma Optical Emission Spectrometry. U.S.A.: The Perkin-Elmer Corporation, 1997.

[31] C. Lao, J. Cotrino, A. Palmero, A. Gamero, and A. R. Gonz'alez-Elipe, "Electron temperature measurement in a surface-wave-produced argon plasma at intermediate pressures," Eur. Phys. J. D, 14 (3), 361-366, 2001.

[32] Nist: http://physics.nist.gov/cgi-bin/ASD/lines1.pl (Erişim Tarihi: 04.06.2015)

[33] Y. H. Jung, and K. S. Chung, "Measurement of the non-thermal properties in a low-pressure spraying plasma,” J. Korean Phys. Soc., 40 (5), 856-860, 2002.

[34] N. Tian-Ye, C. Jin-Xiang, L. Lei, L. Jin-Ying, W. Yan, W. Liang, and L. You, "A comparison among optical emission spectroscopic methods of determining electron temperature in low pressure argon plasmas," Chin. Phys., 16 (9), 2757-2763, 2007.

[35] F. U. Khan, N. U. Rehman, S. Naseer, M. A. Naveed, A. Qayyum, N. A. D. Khattak, and M. Zakaullah, "Diagnostic of $13.56 \mathrm{MHz}$ RF sustained Ar-N2 plasma by optical emission spectroscopy,” Eur. Phys. J. Appl. Phys., 45, 11002, 2009.

[36] D. Karabourniotis, E. Drakakis, and B. Zacharopoulos, "Electron and population temperatures in a non-LTE optically thick plasma" J. Phys. D: Appl. Phys., 25 (2), 188, 1992.

[37] G. Herzberg, Atomic Spectra and Atomic Structure. New York: Dover, 1944.

[38] T. Fujimoto, "Kinetics of ionization-recombination of a plasma and population density of excited ions. I. equilibrium plasma," J. Phys. Soc. Jpn., 47(1), 265-272, 1979.

[39] T. Fujimoto, "Kinetics of ionization-recombination of a plasma and population density of excited ions. IV. Recombining plasma-low-temperature case,” J. Phys. Soc. Jpn., 49 (4), 1569-1576, 1980.

[40] G. V. Marr, Plasma Spectroscopy. London: Elsevier Publishing Company, 1968.

[41] https://fusedweb.llnl.gov/CPEP/Chart_Pages/5.Plasma4StateMatter.html (Erişim Tarihi: 24.07.2019)

[42] M. A. Lieberman, and A. J. Lichtenberg, Principles of Plasma Discharges and Materials Processing. USA: John Wiley and Sons, 2005.

[43] G. Waidmann, “Acoustic perturbations in a pulsed RF-plasma,” Z. Physik, 233 (4), 351-357, 1970.

[44] S. Iordanova, and I. Koleva, "Optical emission spectroscopy diagnostics of inductively-driven plasmas in argon gas at low pressures," Spectrochim. Acta, Part B, 62 (4), 344-356, 2007.

[45] D. O’Connell, T. Gans, D. L. Crintea, U. Czarnetzki, and N. Sadeghi, "Plasma dynamics in an inductively coupled magnetic neutral loop discharge," Plasma Sources Sci. Technol.,17, 024022, 2008. 